\title{
Cigarette and waterpipe smoking among adult patients with severe and persistent mental illness in Bahrain: a comparison with the National Non-communicable Diseases Risk Factors Survey
}

\author{
Randah R. Hamadeh ${ }^{*}$, Ahmed Al Ansari ${ }^{1,2}$, Haitham Jahrami ${ }^{1,2}$ and Adel Al Offi, ${ }^{1,2}$
}

\begin{abstract}
Background: Smoking has been associated with several types of mental illness namely schizophrenia, depression, bipolar disorders with a prevalence of smoking twice that of the general population. The study objective was to ascertain whether waterpipe tobacco smoking (WTS), cigarette smoking and all types of tobacco smoking are more common among Bahraini patients with severe and persistent mental illness (SPMI) than the general population.

Methods: A cross-sectional study was conducted on 222 adult SPMI both in- and out- patients who attended the Psychiatric Hospital in Bahrain. A 29-item questionnaire, which included sociodemographic variables, pattern and history of psychiatric illness and a comprehensive smoking history, was used. Comparative smoking data were obtained from the Bahraini National Non-communicable Diseases Risk Factors Survey.

Results: The prevalence of smoking of tobacco among SPMI patients was $30.2 \%$ compared to $19.9 \%$ in the general population. The corresponding values for cigarette smoking were 25.2, $13.8 \%$, respectively and for WTS, 11.3, 8.4\%, respectively. SPMI patients were $1.7(95 \% \mathrm{Cl} 1.3,2.4 \%)$ times more likely to be smokers, 2.1 (95\% Cl 1.5, $2.9 \%)$ times, cigarette smokers and $1.4(95 \% \mathrm{Cl} 0.9,1.9 \%)$ times WTS than the general population. SPMI patients smoked at a younger age and consumed more cigarettes than the general population. The mean age started smoking was lower among men than women, similar for cigarettes, and higher for WTS.

Conclusions: The prevalence of smoking among patients with SPMI in Bahrain is twice that of the general population. The findings of the study have implications on the provision of healthcare to mentally ill patients in the country.
\end{abstract}

Keywords: Mental illness, Smoking, Waterpipe, Prevalence, Bahrain

\section{Background}

Smoking is a major determinant of global health. In 2013, it occupied the second rank among the global risk factors, accounted for 6.1 million deaths and 143.5 million DALYs $[1,2]$. It is a major risk factor for several noncommunicable and respiratory diseases and substantially

\footnotetext{
*Correspondence: randah@agu.edu.bh

${ }^{1}$ College of Medicine and Medical Sciences, Arabian Gulf University, P.O. Box 26671, Manama, Kingdom of Bahrain

Full list of author information is available at the end of the article
}

affects the health of fetuses of pregnant women and children exposed to tobacco smoke [3]. Most of the evidence of the effects of smoking is based on cigarette smoking, however the health effects of waterpipe tobacco smoking (WTS) became evident in recent years $[4,5]$.

Although the smoking prevalence has decreased over the past few decades in the general population in most countries, it remains a public health priority as the number of smokers increased significantly as a result of population growth and disproportionately high for distinct groups such as those with severe mental illness [1, 6-8]. 
Smoking has been associated with several types of mental illness namely schizophrenia, depression, anxiety disorders, bipolar disorders and dementia. The prevalence of smoking among those with mental illness is twice that of the general population [7, 9]. Moreover, patients with coronary heart disease were reported to have high levels of depression highlighting the importance of tobacco control in mental illness [10]. Primack and colleagues reported that the associations of mental health problems were stronger for cigarette smoking than WTS [11]. In the United States (US), nearly 1 in 5 adults have some form of mental illness, of whom $36 \%$ smoke cigarettes. In comparison, $21 \%$ of US adults without mental illness smoke cigarettes [12]. Notably, the rate of tobacco use increases three times in the psychiatric population, and in particular, a range of $40-100 \%$ is found among schizophrenics. Up to $90 \%$ of those with schizophrenia smoke cigarettes $[13,14]$. Accordingly, smokers with schizophrenia are $30 \%$ more likely than smokers in the general population to die from cardiovascular disease and $60 \%$ more likely to die from respiratory disease $[15,16]$. The average life expectancy for individuals with schizophrenia is $20 \%$ lower than the general population [17]. Schizophrenic patients may perceive the health risks of cigarette smoking to be less than the normal population [18]. Adults with mental illness smoke $70 \%$ of consumed cigarettes in the US [19]. $40 \%$ of men and $34 \%$ of women with mental illness smoke. Additionally, $48 \%$ of people with mental illness who live below the poverty level smoke, compared with $33 \%$ of those with mental illness who live above the poverty level [12].

Tobacco smoking has attracted the attention of mental health professionals worldwide in recent years. Experts attribute the link between smoking and mental illness to a number of factors, which include the biochemistry of tobacco and nicotine, the nature of mental illnesses and the culture of mental health system [9]. However, most of the research that explored the association between tobacco smoking and mental illness was based on cigarette smoking and not WTS [20].

Little published work has focused on determining the prevalence of tobacco smoking among patients with mental illnesses in Arab and other Middle Eastern countries $[21,22]$ and its comparison to that of the general population. An Egyptian study found no difference in smoking rate among schizophrenic patients with or without obsessive-compulsive symptoms [22]. A recent study from a center in north Iraq reported higher smoking rates for schizophrenic patients compared to other mental disorders and that they had smoked earlier than appearance of their first symptoms [23]. A research from Saudi Arabia reported a prevalence rate of $57.9 \%$ among the male outpatient population compared to $78 \%$ of psychiatric inpatient in Iran $[21,24]$. The prevalence rates of smoking in Saudi patients with different diagnoses were as follows: schizophrenia $56.5 \%$, major depressive disorder (MDD) $59.6 \%$, anxiety disorders $53.0 \%$ and substance abuse $72.0 \%$ [21]. These studies focused on specific psychiatric populations, from limited geographic areas and did not include community population or national smoking statistics.

The Bahraini National Non-communicable Diseases Risk Factors Survey (NNDRFS) in 2007 reported that the prevalence of smoking of all types of tobacco in males, females and both sexes combined in Bahraini nationals was $33.4,7.0$ and $19.9 \%$, respectively [25]. The corresponding figures for cigarette smoking were 27.0, 1.2 and $13.8 \%$, respectively and that of WTS, 10.8, 6.2 and $8.4 \%$, respectively. No previous studies have been under taken in Bahrain to examine the prevalence of smoking among patients with mental illness.

The Psychiatric Hospital in Bahrain is the main and only public services facility for mental illness in the country. In 2012, 405 patients were admitted to the Psychiatric Hospital in the age group 15-64 years. 232 were diagnosed with schizophrenia, 97 bipolar affective disorder (BAD) and 77 MDD according to the Ministry of Health's 2012 Annual Report [26]. The objective of this study was to ascertain whether WTS, cigarette smoking and all types of tobacco smoking are more common among Bahraini patients with severe and persistent mental illness (SPMI) than the general population (NNDRFS).

\section{Methods}

A cross sectional study was conducted on adult (2064 years) Bahraini outpatients and inpatients who attended the Psychiatric Hospital in Bahrain with SPMI from 1 November 2014 to 31 January 2015.

The Psychiatric Hospital was founded in 1932. The hospital has 246 inpatient beds (16-beds for alcohol and drug dependence patients, 55 for acute patients, 40 for short-stay patients, 10 for child psychiatry, 80 for longstay patients and 45 for the intellectual disabilities). The Psychiatric Hospital is considered to be the main center for psychiatric care services in the country. The hospital works for $24 \mathrm{~h}$ and accepts psychiatric disorder and social cases which come directly or are referred from other hospitals and health centers.

A convenient sample of 240 SPMI patients, which included schizophrenia, BAD and MDD classified according to the International Classification of Disease (ICD 10) criteria was selected. SPMI patients whose mental status did not allow them to be interviewed or had comorbidity with other psychiatric diagnoses were excluded from the study. Convenience non-probabilistic sampling technique was the most applicable and 
feasible technique in this research due to the nature of the research topic. The sample size was determined using the prevalence of smoking in Bahrain (19.9\%) based on that reported in the NNDRFS, alpha of 0.05 and a beta of 0.80 . This resulted in a minimum sample size of 210 patients. Data collection included all of the general adult psychiatric clinics in the hospital on all working days of the week during the 2 months data collection period. Eighteen patients refused to participate in the study mostly due to transport related matters and 222 accepted.

Two independent, trained hospital staff collected the data for this research during a semi-structured interview session. These patients were regularly following up their treatment appointments with psychiatrists, and had been seen on many previous occasions by a multidisciplinary team, thus comprehensive data had been recorded in their medical record files. These files were reviewed for abstracting socio-demographic characteristics, diagnosis, and clinical history. In addition, the data collection staff interviewed the patients privately and recorded their responses using a 29-item questionnaire, which included questions on smoking history taken from the NNDRFS. The latter used face-to-face interviews similar to the data collection method of the current study. Smokers were defined according to those used in the NNDRFS to allow comparisons. Smoking status was categorized into current daily, current occasional, ex- and non-smokers. Smokers were classified according to tobacco types as cigarette (manufactured and hand-rolled), shisha (waterpipe) or other types (cigar or pipe) smokers. Average number of cigarettes smoked daily was calculated for daily smokers only [25].

The researchers briefed each patient as well as key relatives regarding this study. Participating patients gave their consent prior to interview and those who refused were excluded.

Data was entered and analyzed using the SPSS version 22.0. Chi-square test, independent samples $t$ test and ANOVA were used where applicable. The $\mathrm{p}$ value was considered significant at $<0.05$. The standardized smoking prevalence ratios (SSPR) were calculated similar to the method used to calculate standardized mortality ratios. To get the expected number of smokers, the age specific smoking rates from each age group in the standard population were multiplied by the corresponding number of SPMI in that age group. The total expected number of smokers was obtained by summing the expected numbers of smokers in each age group. The observed total number of smokers among the SPMI was divided by the expected number of smokers and then multiplied by 100 to get SSPR. This was repeated for all types of smoking, cigarettes and WTS. The corresponding $95 \%$ confidence intervals were calculated for SSPR.
Ethical approval was attained from the Research Technical and Support Committee, Ministry of Health, Kingdom of Bahrain.

\section{Results}

Of the 222 SPMI patients (46 inpatients and 176 outpatients), there were 99 with schizophrenia (44.6\%), 86 BAD (38.7 \%) and 37 (16.7\%) MDD. Table 1 show that the majority of the patients were in the age groups 40-49 and 30-39. The SPMI patients were almost similar with respect to gender but there was a significantly lower percentage $(p=0.002)$ of females among schizophrenia, half that of MDD. About $40.0 \%$ of SPMI patients had less than a high school degree and over half had a monthly family income of 150-500 BD (398-1327 US \$). Only $21.2 \%$ of SPMI patients were employed with statistically significant $(\mathrm{p}<0.0001)$ differences between the patients of the three clinical categories.

Sixty eight percent of SPMI patients were diagnosed for over 5 years. The corresponding proportions for schizophrenia, BAD and MDD were 79.8, 55.8, 64.0 \%, respectively ( $\mathrm{p}<0.0001$ ). The mean outpatient visits during 2014 of SPMI patients were 6.9 (95\% CI 6.3, 7.5) with slight variation between the diagnoses (schizophrenia, 7.3 (95\% CI 6.2, 8.3), MDD 6.6 (95\% CI 5.7, 7.5) and BAD 6.6 (95\% CI 5.1, 8.2). There was a statistically significant difference in the number of admissions to the Psychiatric Hospital ( $\mathrm{p}<0.0001$ ) with over one third of schizophrenic patients $(35.4 \%)$ having over six admissions in the past 5 years compared to $5.8 \%$ of BAD, $27.0 \%$ MDD and $22.5 \%$ for all SPMI patients.

Almost one third of the SPMI patients were smokers (30.2\%, $95 \%$ CI 24.2, $36.7 \%$ ). The prevalence of smoking was higher in men $(47.7 \%, 95 \%$ CI 38.1, $57.5 \%)$ compared to $13.3 \%$ for women (Table 2). Cigarette smoking (46.8\%, $95 \%$ CI 37.2, $56.6 \%$ ) was more popular than WTS (11.0 \%, $95 \%$ CI 5.8.1, 18.4\%) among men. In contrast, WTS (11.5\%, $95 \%$ CI 6.3, $18.9 \%)$ was almost double that of cigarette smoking (4.4\%, $95 \%$ CI 1.4, $10.0 \%)$ among women. The prevalence of WTS was similar in both sexes. The differences among the clinical categories with respect to smoking were not significant except for cigarette smoking in both genders. In both sexes combined and among men, BAD had the highest prevalence of smoking any type of tobacco (35.1\%, $95 \%$ CI 20.2, 52.5 and $58.8 \%$, $95 \%$ CI 32.9, 81.6\%, respectively).

SPMI had higher proportions of ever tobacco smokers in males $(83.5 \%)$, females (3.2\%) and both sexes combined (57.2\%) than those reported in the NNDRFS (48.7, 1.1, $29.5 \%$, respectively). The percentages for former smokers of any type of tobacco in SPMI males (35.8\%), females (18.5\%) and both sexes combined (27.0\%) were also higher than in the NNDRFS (15.3, 4.1, 9.6\%, 
Table 1 Sociodemographic characteristics of SPMI patients

\begin{tabular}{|c|c|c|c|c|c|c|c|c|}
\hline & \multicolumn{2}{|c|}{$\begin{array}{l}\text { Schizophrenia } \\
(n=99)\end{array}$} & \multicolumn{2}{|c|}{$\begin{array}{l}\text { MDD } \\
(n=86)\end{array}$} & \multicolumn{2}{|c|}{$\begin{array}{l}\text { BAD } \\
(n=37)\end{array}$} & \multicolumn{2}{|c|}{$\begin{array}{l}\text { Total } \\
(n=222)\end{array}$} \\
\hline & No. & $\%$ & No. & $\%$ & No. & $\%$ & No. & $\%$ \\
\hline \multicolumn{9}{|l|}{ Gender* } \\
\hline Male & 61 & 61.6 & 31 & 36.0 & 17 & 45.9 & 109 & 49.1 \\
\hline Female & 38 & 38.4 & 55 & 64.0 & 20 & 54.1 & 113 & 50.9 \\
\hline \multicolumn{9}{|l|}{ Age } \\
\hline $20-29$ & 18 & 18.2 & 13 & 15.1 & 9 & 24.3 & 40 & 18.0 \\
\hline $30-39$ & 27 & 27.2 & 14 & 16.3 & 9 & 24.3 & 50 & 22.5 \\
\hline $40-49$ & 25 & 25.3 & 27 & 31.4 & 9 & 24.3 & 61 & 27.5 \\
\hline $50-59$ & 17 & 17.2 & 16 & 18.6 & 7 & 18.9 & 40 & 18.0 \\
\hline $60-64$ & 12 & 12.1 & 16 & 18.6 & 3 & 8.2 & 31 & 14.0 \\
\hline \multicolumn{9}{|l|}{ Education } \\
\hline Illiterate & 9 & 9.1 & 6 & 7.0 & 2 & 5.4 & 17 & 7.7 \\
\hline Read and write & 7 & 7.1 & 6 & 7.0 & 1 & 2.7 & 14 & 6.2 \\
\hline Primary & 12 & 12.1 & 7 & 8.0 & 4 & 10.8 & 23 & 10.4 \\
\hline Intermediate & 17 & 17.2 & 12 & 14.0 & 6 & 16.2 & 35 & 15.8 \\
\hline High school & 40 & 40.4 & 35 & 40.7 & 15 & 40.5 & 90 & 40.5 \\
\hline University & 14 & 14.1 & 20 & 23.3 & 9 & 24.4 & 43 & 19.4 \\
\hline \multicolumn{9}{|l|}{ Income (BD) } \\
\hline$<150$ & 28 & 28.3 & 13 & 15.1 & 7 & 18.9 & 48 & 21.6 \\
\hline $150-500$ & 45 & 45.5 & 50 & 58.1 & 19 & 51.4 & 114 & 51.4 \\
\hline$>500$ & 26 & 26.3 & 23 & 26.7 & 11 & 29.7 & 60 & 27.0 \\
\hline \multicolumn{9}{|l|}{ Employment** } \\
\hline Employed & 14 & 14.2 & 22 & 25.6 & 11 & 29.7 & 47 & 21.2 \\
\hline Not employed & 53 & 53.5 & 17 & 19.8 & 9 & 24.3 & 79 & 35.6 \\
\hline Housewife & 18 & 18.1 & 32 & 37.2 & 8 & 21.6 & 58 & 26.1 \\
\hline Retired & 14 & 14.2 & 15 & 17.4 & 9 & 24.3 & 38 & 17.1 \\
\hline
\end{tabular}

${ }^{*} p<0.005 ;{ }^{* *} p<0.0001$

Table 2 Prevalence of smoking of SPMI patients by diagnosis, gender and type

\begin{tabular}{|c|c|c|c|c|c|}
\hline Type & Schizophrenia & MDD & BAD & Total $^{a}$ & $p$ value \\
\hline \multicolumn{6}{|l|}{ Male } \\
\hline Cigarettes & $49.2(36.1,62.3)$ & $35.5(19.2,54.6)$ & $58.8(32.9,81.6)$ & $46.8(37.2,56.6)$ & 0.445 \\
\hline Waterpipe & $9.8(3.7,20.2)$ & $16.1(5.5,33.7)$ & $5.9(0.1,28.7)$ & $11.0(5.8,18.4)$ & 0.504 \\
\hline Any type & $49.2(36.1,62.3)$ & $38.7(21.9,57.8)$ & $58.8(32.9,81.6)$ & $47.7(38.1,57.5)$ & 0.387 \\
\hline \multicolumn{6}{|l|}{ Female } \\
\hline Cigarettes & $2.6(0.1,13.8)$ & $5.5(1.1,1.5)$ & $5.0(1.3,24.9)$ & $4.4(1.4,10.0)$ & 0.802 \\
\hline Waterpipe & $5.3(0.6,17.7)$ & $14.5(6.5,26.7)$ & $15.0(3.2,37.9)$ & $11.5(6.3,18.9)$ & 0.334 \\
\hline Any type & $7.9(1.7,21.4)$ & $16.4(7.8,28.8)$ & $15.0(3.2,37.9)$ & $13.3(7.6,20.9)$ & 0.481 \\
\hline \multicolumn{6}{|l|}{ Both sexes } \\
\hline Cigarettes & $31.3(22.4,41.4)$ & $16.3(9.2,25.8)$ & $29.7(15.9,47.0)$ & $25.2(19.7,31.5)$ & 0.050 \\
\hline Waterpipe & $8.1(3.6,15.3)$ & $15.1(8.3,24.5)$ & $10.8(3.0,25.4)$ & $11.3(7.4,16.2)$ & 0.318 \\
\hline Any type & $33.3(24.2,43.5)$ & $24.4(15.8,34.9)$ & $35.1(20.2,52.5)$ & $30.2(24.2,36.7)$ & 0.324 \\
\hline
\end{tabular}

a $95 \% \mathrm{Cl}$

respectively). The prevalence of current smoking of any type of tobacco among SPMI patients was $30.2 \%$ compared to $19.9 \%$ in the general population $(\mathrm{p}=0.001)$. The corresponding values for cigarette smoking were $25.2 \%$, 13.8 , respectively $(\mathrm{p}<0.0001)$ and for WTS $11.3,8.4 \%$, respectively. $62.7 \%$ of smokers among SPMI patients 
smoked cigarettes only compared to $53.7 \%$ of the population, $16.4 \%$ WTS only compared to $26.4,20.9 \%$ mixed compared to $15.9 \%$. None of the SPMI smokers smoked cigar or pipe compared to $4.0 \%$ of the general population.

Male SPMI patients were 1.8 times more likely to be smokers and 2.4 times to be cigarette smokers than the general population but similar with respect to WTS. As for women patients with SPMI, they were 2.0 times more likely to be smokers and WTS and 3.8 times to be cigarette smokers than the general population. The odds ratios for both sexes combined were 1.7, 2.1 and 1.4, respectively (Table 3 ). The SSPR for cigarette smoking among SPMI patients was 190 (95\% CI 144, 247 \%). The corresponding SSPRs for WTS and all type of smoking were 85 (95\% CI 55, $126 \%$ ) and 153 (95\% CI 119, $194 \%$ ), respectively. All SPMI patients who smoked cigarettes were daily smokers compared to $96.3 \%$ of the cigarette smokers in the population. As for WTS, $45.6 \%$ were occasional smokers in the population compared to none among SPMI patients. Further, a higher percentage of SPMI patients were former smokers $(27.0 \%)$ than

Table 3 Prevalence rates of smoking by gender and type: comparison with the general population

\begin{tabular}{llll}
\hline & $\begin{array}{l}\text { SPMI } \\
\text { patients }\end{array}$ & $\begin{array}{l}\text { General } \\
\text { population }\end{array}$ & OR (95 \%Cl) \\
\hline Male & & & \\
Cigarettes & 46.8 & 27.1 & $2.4(1.6,3.5)$ \\
Waterpipe & 11.0 & 10.8 & $1.0(0.5,1.9)$ \\
Any type & 47.7 & 33.4 & $1.8(1.2,2.7)$ \\
Female & & & \\
Cigarettes & 4.4 & 1.2 & $2.8(1.3,11.0)$ \\
Waterpipe & 11.5 & 6.2 & $2.0(1.0,3.7)$ \\
Any type & 13.3 & 7.1 & $2.0(1.1,3.7)$ \\
Both sexes & & & $2.1(1.5,2.9)$ \\
Cigarettes & 25.2 & 13.8 & $1.4(0.9,1.9)$ \\
Waterpipe & 11.2 & 8.4 & $1.7(1.3,2.4)$ \\
Any type & 30.2 & 19.9 & \\
\hline
\end{tabular}

the population $(9.6 \%)$. The corresponding proportions among men were $35.8,15.3 \%$, respectively and women $18.5,4.1 \%$, respectively.

The mean age started smoking any tobacco was lower among men (15.9 \pm 0.5 years) than women (18.0 \pm 7.3 years), similar for cigarettes $(15.9 \pm 0.5$ and $16.0 \pm 6.4$, respectively) but higher for WTS $(24.2 \pm 8.9$ and $18.8 \pm 7.7$, respectively (Table 4 ). The differences between the SPMI categories were not statistically significant. Further, the mean age at starting to smoke among SPMI patients was lower than the general population for all age groups but the differences were statistically significant only for the age group 20-29 years. MDD patients started to smoke at a younger age $(15.3 \pm 5.1)$ than schizophrenics $(16.2 \pm 3.8)$ and BAD $(18.5 \pm 5.2)$. Moreover, SPMI patients started cigarette smoking at a younger age than the general population in both sexes (Table 5).

Male, female and both sexes combined of SPMI patients consumed higher number of cigarettes daily compared to the general population (Table 6). There were no statistically significant differences among the SPMI categories with respect to tobacco consumption. The average number of cigarettes per day was highest among schizophrenia patients in men, women and both sexes and MDD for WTS per week.

\section{Discussion}

One third of SPMI in both sexes combined and half of the males were smokers. The number of smokers among SPMI was twice that of the general population for all types. This finding is consistent with some reported studies $[7,27,28]$. Such high prevalence of smoking among SPMI patients would increase the risk of smoking related health complications and death from vascular diseases, cancer and other disease conditions [29, 30]. Article 4 of the Bahrain 2009 Antismoking Law prohibits tobacco smoking in closed public places including health establishments; however the majority of the SPMI in the study was outpatients and could smoke freely outside the hospital premises. As for inpatients they generally smoked

Table 4 Mean age started smoking by tobacco type and mental disorder

\begin{tabular}{|c|c|c|c|c|c|c|c|c|c|c|c|c|}
\hline \multirow[t]{2}{*}{ Mental disorder } & \multicolumn{4}{|c|}{$\begin{array}{l}\text { Cigarette smoking } \\
(n=56)\end{array}$} & \multicolumn{4}{|c|}{$\begin{array}{l}\text { WP smoking } \\
(n=25)\end{array}$} & \multicolumn{4}{|c|}{$\begin{array}{l}\text { All types } \\
(n=67)\end{array}$} \\
\hline & Mean & SD & $95 \%$ & $\mathrm{Cl}$ & Mean & SD & $95 \%$ & $\mathrm{Cl}$ & Mean & SD & $95 \%$ & $\mathrm{Cl}$ \\
\hline Schizophrenia & 16.0 & 3.8 & 14.9 & 17.4 & 22.3 & 8.1 & 15.5 & 29.0 & 16.2 & 3.8 & 14.9 & 17.6 \\
\hline MDD & 15.0 & 3.9 & 12.8 & 17.2 & 18.8 & 9.2 & 13.3 & 24.4 & 15.3 & 5.1 & 13.0 & 17.7 \\
\hline BAD & 16.9 & 3.5 & 14.5 & 19.3 & 27.8 & 3.2 & 22.7 & 32.8 & 18.5 & 5.2 & 15.4 & 21.7 \\
\hline Total & 15.9 & 3.7 & 14.9 & 16.9 & 21.4 & 8.5 & 17.8 & 24.9 & 16.4 & 4.6 & 15.3 & 17.5 \\
\hline F & 0.804 & & & & 1.844 & & & & 2.062 & & & \\
\hline$p$ value & 0.453 & & & & 0.182 & & & & 0.136 & & & \\
\hline
\end{tabular}


Table 5 Mean age started cigarette smoking of SPMI patients by gender: comparison with the general population

\begin{tabular}{lcccc}
\hline & Number & Mean & Std. deviation & p value \\
\hline Male & & & & \\
SPMI & 51 & 30.5 & 19.7 & $<0.0001$ \\
NNDRFS & 224 & 19.4 & 12.5 & \\
Female & & & & 0.170 \\
SPMI & 5 & 23.0 & 16.4 & \\
NNDRFS & 11 & 10.2 & 7.2 & $<0.0001$ \\
Both sexes & & & & \\
SPMI & 56 & 29.8 & 19.5 & \\
NNDRFS & 235 & 18.9 & 12.5 & \\
\hline
\end{tabular}

Table 6 Average number of cigarettes smoked daily by SPMI patients and the general population by gender

\begin{tabular}{lclc}
\hline Gender & SPMI & General population & p value \\
\hline Male & $30.5 .4 \pm 19.7$ & $19.4 \pm 12.5$ & $<0.0001$ \\
Female & $23.0 \pm 16.4$ & $10.2 \pm 7.2$ & 0.170 \\
Both sexes & $29.8 \pm 19.5$ & $18.9 \pm 12.5$ & $<0.0001$ \\
\hline
\end{tabular}

outside the building but for those who were unable to go out (none of the study population were in this category) they have an allocated room for them to smoke. This raises the question whether the Psychiatric Hospital should continue to permit smoking for those patients irrespective of the law or completely prohibit it $[31,32]$.

WTS among SPMI patients was 1.5 times that of the general population. Comparative data of WTS among mentally ill patients in the region is scarce as WTS and mental illness was not well researched in the region. It is noteworthy that Nejad and Pouga reported similar figures of hookah smoking rate among inpatients with SPMI in Iran [33]. The finding that cigarette smoking was higher in both sexes among SPMI compared to the population is expected. Given that SPMI use tobacco more than the general population, it is not surprising that SPMI women had higher rates of WTS as it is more culturally acceptable for women to smoke waterpipe than cigarettes. In contrast, any type of tobacco use by men is socially tolerated. Further, the higher daily consumption of cigarettes by SPMI patients compared to the general population is consistent with the literature as these patients tend to use cigarettes to alleviate their symptoms [33].

Another important finding was that more than one third of male SPMI patients who ever smoked (35.8\%) quit smoking compared to $15.3 \%$ from the same gender in the general population. This indicates even a higher smoking prevalence among this vulnerable population.
Cigarette smoking was higher among schizophrenia and BAD patients compared to those with MDD $(\mathrm{p}=0.050)$. SPMI patients may use smoking as a way of self-medication to alleviate symptoms and improve cognition [33, 34].

Furthermore, high smoking rates among SPMI patients support some theories that try to explain why mentally ill patients smoke more than the general population. It has been reported that nicotine derivatives interfere with the metabolism of some of the antipsychotic medication and can affect blood drug levels [35, 36]. It could be that psychotic patients smoke in order to reduce the effect of these medications and their side effects. The finding that SPMI patients smoke at a younger age and consume more cigarettes than the general population further supports studies from other parts of the world [7].

The study had some limitations as the sample included patients with long mental illness history and frequent hospital admissions, which might make them possibly different from SPMI patients in the community. Further, the prevalence of smoking in the general population was based on those of 2007; the only available data and the time lag between NNDRFS and this study cannot be overlooked. Finally, the generalizability of the findings is limited since convenience sampling in the selection of the study population was used.

The major strength of this study is that it is the first of its kind in the Eastern Mediterranean Region as it compares mentally ill patients with the general population with respect to cigarette smoking, WTS and all types of tobacco smoking in both sexes.

The implication of the research results on policy and practice at the Psychiatric Hospital include abolishing the use of cigarettes as an incentive in long stay wards, introducing smoking related questions in the personal history of patients, adding the subject of smoking to the psychoeducation program of schizophrenic patients and providing smoking cessation assistance to smokers. Smokers can be referred by their psychiatrists to the Quit Tobacco Clinics (QTC) as these clinics are available free of charge to any smoker intending to quit or has been referred by the physician. Further, the Ministry of Health might consider opening a QTC at the Psychiatric hospital as the QTC are located in the primary healthcare centers of the ministry.

\section{Conclusions}

The findings of this study highlight the importance of smoking prevention and cessation programmes. All efforts should be mobilized to strengthen tobacco control measures in the country and modify the hospital policies and regulations to control tobacco use. Moreover, including tobacco use in personal history and providing 
smoking cessation assistance to smokers needs to be seriously considered. Further, the practice of giving tobacco as an incentive should be stopped. In addition, fostering healthy lifestyle for patients with mental illness should be part of their management.

\begin{abstract}
Abbreviations
SPMI: severe and persistent mental IIness; WTS: waterpipe tobacco smoking; NNDRFS: National Non-communicable Diseases Risk Factors Survey; MDD: major depressive disorder; BAD: bipolar affective disorder; ICD 10: international classification of diseases version 10; SSPR: standardized smoking prevalence ratios.
\end{abstract}

\section{Authors' contributions}

RH has made substantial contributions to conception and design, acquisition of funding and analysis and interpretation of data; has been involved in drafting the manuscript and revising it critically for important intellectual content. AA has made substantial contributions to conception and design of the study; has been involved in drafting the manuscript and revising it critically for important intellectual content. HJ has made substantial contributions to supervising the acquisition of data, and analysis and interpretation of data; has been involved in drafting the manuscript and revising it critically for important intellectual content. AO has made substantial contributions in seeking approval for the research, and has given final approval of the version to be published. All authors read and approved the final manuscript.

\section{Author details}

${ }^{1}$ College of Medicine and Medical Sciences, Arabian Gulf University, P.O. Box 26671, Manama, Kingdom of Bahrain. ${ }^{2}$ Psychiatric Hospital, Ministry of Health, P.O. Box 5128, Manama, Kingdom of Bahrain.

\section{Acknowledgements}

This study was supported by a seed grant from the Syrian Center for Tobacco Studies and the American University of Beirut Tobacco Control Research Group.

\section{Competing interests}

The authors declare that they have no competing interests.

Received: 22 October 2015 Accepted: 29 January 2016

Published online: 09 February 2016

\section{References}

1. GBD 2013 Risk Factors Collaborators, Forouzanfar MH, Alexander L, Anderson HR et al. Global, regional and national comparative risk assessment of 79 behavioural, environmental/occupational and metabolic risks or clusters of risks in 188 countries 1990-2013: a systematic analysis for the GBD 2013. Lancet. 2015; (15): 00128-2. Published online September 11, 2015. doi:10.1016/S0140-6736.

2. Lim SS, Vos T, Flaxman AD, et al. A comparative risk assessment of burden of disease and injury attributable to 67 risk factors and risk factor clusters in21 regions, 1990-2010: a systematic analysis for the Global Burden of Disease Study 2010. Lancet. 2012;380(9859):2224-60.

3. Ezzati M, Riboli E. Behavioral and dietary factors for non-communicable diseases. N Eng J Med. 2013;369(10):954-64.

4. El-Zaatari ZM, Chami HA, Zaatari GS. Health effects associated with waterpipe smoking. Tob Control. 2015;24:131-43. doi:10.1136/ tobaccocontrol-2014-051908.

5. AkI EA, Gaddam S, Gunukula SK, Honeine R, Abou Jaoude P, Irani J. The effects of waterpipe tobacco smoking on health outcomes: a systematic review. Int J Epidemiol. 2010;39:834-57.

6. Ng M, Freeman MK, Fleming TD, Robinson M, Dwyer-Lindgren L, Thomson B, Wollum A, Sanman E, Wulf S, Lopez AD, Murray CJL, Gakidou E. Smoking prevalence and cigarette consumption in 187 countries, 1980-2012. J Am Med Assoc. 2014;311(2):183-92. doi:10.1001/ jama.2013.284692.

7. Lasser K, Boyd W, Woolhandler S, Himmelstein DU, McCormick D, Bor DH. Smoking and mental illness: a population-based prevalence study Free. JAMA. 2000;284(20):2606-10.

8. Aubin HJ, Rollema H, Svensson TH, Winterer G. Smoking, quitting and psychiatric disease: a review. Neurosci Biobehav. 2012;36(1):271-84.

9. Prochaska JJ, Hall SM, Bero LA. Tobacco use among individuals with schizophrenia: what role has the tobacco industry played? Schizophr Bull. 2008;34(3):555-67.

10. Duivis HE, de Jonge P, Penninx BW, Na BY, Cohen BE, Whooley MA. Depressive symptoms, health behaviors, and subsequent inflammation in patients with coronary heart disease: prospective findings from the Heart and Soul Study. Am J Psychiatry. 2011;168:913-20.

11. Primack BA, Land SR, Fan J, Kim KH, Rosen DA. Associations of mental health problems with waterpipe tobacco and cigarette smoking among college students. Subs Use Misuse. 2013;48(3):211-9.

12. Centers for Disease Control and Prevention. Vital signs: current cigarette smoking among adults aged $\geq 18$ years_-United States, 2009. Morb Mortal Wkly Rep. 2010;59:1135-40.

13. de Leon J, Becoña E, Gurpegui M, Gonzalez-Pinto A, Diaz FJ. The association between high nicotine dependence and severe mental illness may be consistent across countries. J Clin Psychiatry. 2002;63:812-6.

14. de Leon J, Diaz FJ. A meta-analysis of worldwide studies demonstrates an association between schizophrenia and tobacco smoking behaviors. Schizophr Res. 2005;76:135-57.

15. Baxter DN. The mortality experience of individuals on the Salford Psychiatric Case Register. I. All cause mortality. Br J Psychiatry. 1996;168(6):772-9.

16. Dalack GW, Healy DJ, Meador-Woodruff JH. Nicotine dependence in schizophrenia: clinical phenomena and laboratory findings. Am J Psychiatry. 1998;155:1490.

17. Hennekens $\mathrm{CH}$, Hennekens AR, Hollar D, Casey DE. Schizophrenia and increased risks of cardiovascular disease. Am Heart J. 2005;150:1115-21.

18. Kelly DL, Raley HG, Lo S, et al. Perception of smoking risks and motivation to quit among nontreatment-seeking smokers with and without schizophrenia. Schizophr Bull. 2012;38:543-51.

19. Grant BF, Hasin DS, Chou SP, Stinson FS, Dawson DA. Nicotine dependence and psychiatric disorders in the United States. Arch Gen Psychiatry. 2004:61:1107-15.

20. Ziedonis D, Hitsman B, Beckham JC, Zvolensky M, Adler LE, AudrainMcGovern J, Breslau N, Brown RA, George TP, Williams J, Calhoun PS, Riley WT. Tobacco use and cessation in psychiatric disorders: National Institute of Mental Health report. Nicotine Tob Res. 2008;10(12):1691-715.

21. Al-Habeeb TA, Qureshi NA. Smoking among male psychiatric outpatients in Saudi Arabia. Ann Saudi Med. 2000;20(3-4):218-23.

22. Fawzi MH, Fawzi MM, Khedr HH, Fawzi MM. Tobacco smoking in Egyptian schizophrenia patients with and without obsessive-compulsive symptoms. Schizophr Res. 2007;95(1-3):236-46.

23. Rahim TA, Muhyadin AS. Nicotine dependence among a group of Iraqi schizophrenic patients. Iraqi Postgrad Med J. 2011;10(1):89-94.

24. Milani HS, Kharaghani R, Safa M, Samadi R, Farhadi M, Ardakani M, Masjedi MR. Pattern of smoking and nicotine dependence in patients with psychiatric disorders. Tanaffos. 2012;11 (1):55-60.

25. Alsayyad J, Omran A, Amin FA, Hamadeh RR. National Non-Communicable Diseases Risk Factors Survey 2007. Bahrain: Ministry of Health, UNDP Country Programme with the Government of Bahrain; 2010. ISBN 978-99958-6101-8.

26. Ministry of Health. Health statistics 2012. Manama, Kingdom of Bahrain. http://www.moh.gov.bh/PDF/Publications/statistics/HS2012/hs2012_e. $\mathrm{htm}$.

27. Hughes JR, Hatsukami DK, Mitchell JE, Dahlgren LA. Prevalence of smoking among psychiatric outpatients. Am J Psychiatry. 1986;143(8):493-7.

28. Glassman AH. Cigarette smoking: implications for psychiatric illness. Am J Psychiatry. 1993;150:546-53.

29. Bruce ML, LeaP PJ, Rozal GP, Floria L, Hoff RA. Psychiatric status and 9 years mortality data in the New Haven Epidemiologic Catchment Area Study. AMJ Psychiatry. 1994;151:716-21. Retrieved from http://www.cdc.gov/ $\mathrm{mmwr} /$ preview/mmwrhtml/mm5935a3.htm. 
30. US Deptartment of Health and Human Services. The health consequences of smoking: a report of the Surgeon General. Washington: US Department of Health and Human Services; 2004.

31. Bahrain Law No. 8 of 2009 on anti-smoking and tobacco types. Retrieved January 25, 2016, from http://www.legalaffairs.gov.bh/LegislationSearchDetails.aspx?id=2192\#.VqYzFfl94dU.

32. Ratschen E, Britton J, Doody GA, McNeill A. Smoke-free policy in acute mental health wards: avoiding the pitfalls. Gen Hosp Psychiatry. 2009;31(2):131-6. doi:10.1016/j.genhosppsych.2008.10.006 (Epub 2008 Dec 5)
33. Nejad AG, Pouya F. Nicotine and opium dependence in psychiatric patients. Neurosciences. 2004;9(1):49-53.

34. Lavin MR, Siris SG, Mason SE. What is the clinical importance of cigarette smoking in schizophrenia? AMJ Addict. 1996:5:189-208.

35. Lucas C, Martin J. Smoking and drug interactions. Aust Prescr. 2013;36:102-4.

36. Kroon LA. Drug interactions with smoking. Am J Health-Syst Pharm. 2007;64:1917-21.
Submit your next manuscript to BioMed Central and we will help you at every step:

- We accept pre-submission inquiries

- Our selector tool helps you to find the most relevant journal

- We provide round the clock customer support

- Convenient online submission

- Thorough peer review

- Inclusion in PubMed and all major indexing services

- Maximum visibility for your research

Submit your manuscript at www.biomedcentral.com/submit
(O) BioMed Central 